\title{
ARTICLES
}

\section{Functional Analysis of a Rare HBV Deletion Mutant in Chronically Infected Children}

\author{
PATRICK GERNER, HEIKE MARIE CLARA SCHÄFER, REINHILD PRANGE, \\ DIRK PRAVITT, AND STEFAN WIRTH
}

Children's Hospital, Helios Klini Kum, Wuppertal [P.G., S.W.], Wuppertal, Germany; Institut für Medizinische Mikrobiologie und Hygiene [H.M.C.S., R.P.], Johannes Gutenberg-University, Mainz, Germany; and Children's Hospital [D.P.], Johannes Gutenberg-University, Mainz, Germany

\begin{abstract}
ABSTR
Liver damage caused by chronic hepatitis B virus (HBV)
infection may be enhanced through the selection of deleted HBV
preS mutants by intracellular accumulation of viral proteins and
subsequent cell death. However, the prevalence and impact of
such mutants on the clinical course of infection have not yet been
studied in children. Serum samples from 60 children (mean age
9.8 y) were investigated by means of PCR and direct sequencing
of the entire preS region. Only one patient (1.5\%) was found with
a mixed HBV population of a deletion spanning 183 nucleotides
and wild-type sequences. This mutation alters the HBV large-
surface protein and removes the small-surface promoter. To
clarify the significance of this mutation, we studied 14 serial
serum samples of the child within a follow-up of 10 y. After
occurrence of the mutation, the liver enzymes increased, despite
seroconversion to anti-HBe. Transfection of an HBV expression
construct containing this deletion into human hepatoma cells by
\end{abstract}
using an $\mathrm{HBV}$ in vitro replication system showed that the mutant lost the ability of nucleocapsid packaging as a result of alteration of the transmembrane topology of the large surface protein. This effect could not be restored by coexpression of wild-type largeor small-surface proteins in trans. In conclusion, the circulation of HBV preS deletion mutants is rare in childhood. However, our functional and clinical follow-up studies in one child suggest that such a mutant may have the potential to aggravate liver inflammation, especially if corroborated with larger numbers of children. (Pediatr Res 53: 891-897, 2003)

HBV, hepatitis B virus
Nt, nucleotide
ER, endoplasmic reticulum
EPR, endogenous polymerase reaction

Recent investigations in hepatitis B virus (HBV) mutant strains have demonstrated a direct influence of the viral genome on the clinical course of infection (1-6; for review, see $7,8)$. However, in most of these studies, the patients were under exceptional courses of HBV infection, such as immunosuppression or fulminant liver failure, and therefore only a limited number of subjects have been analyzed. Thus, more evidence that HBV variants can also become clinically relevant for chronic carriers with common courses of infection is still required.

Mutations in the HBV envelope preS region have been shown to be associated with ongoing liver disease both on the

Received June 20, 2001; accepted April 23, 2002.

Correspondence: Prof. Dr. Stefan Wirth, Children's Hospital, Helios Klini Kum, Wuppertal, Heusnerstrasse 40, D-42283 Wuppertal, Germany; e-mail: swirth@ helios-klinikum.de

This work was supported by Deutsche Forschungsgemeinschaft, No. WI 991/3-2.

DOI: 10.1203/01.PDR.0000064906.63939.72 clinical and the functional level $(9-11)$. This is due to the pivotal function of surface peptides in virus morphogenesis that envelop the DNA-containing capsid with three viral proteins, termed the large (L), middle (M), and small (S) envelope proteins. These polypeptides are encoded in a single open reading frame of the $\mathrm{HBV}$ genome that contains three start codons and a common stop codon. Accordingly, the $\mathrm{S}$ region is translated by all three proteins, whereas $\mathrm{M}$ and $\mathrm{L}$ are synthesized with amino-terminal extensions encoding the preS2 region and the preS2 plus preS1 region (preS), respectively (see Fig. 1). Among the three envelope proteins, particularly the $\mathrm{L}$ protein has a crucial role in the viral life cycle. It has the unusual ability to adopt two transmembrane topologies in the endoplasmic reticulum (ER) membrane (see Fig. 2 (9). The cytosolic orientation of $\mathrm{L}$ interacts with the nucleocapsid while the luminal orientation is required to localize the preS region on the surface of secreted virions to allow attachment to the $\mathrm{HBV}$ receptor on the hepatocyte. It has been shown that the 
A.

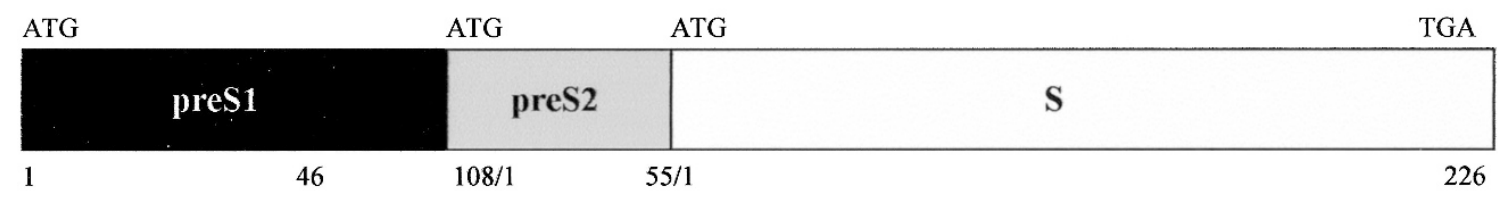

Large (L) envelope protein

Middle (M) envelope protein

Small (S) envelope protein

B.

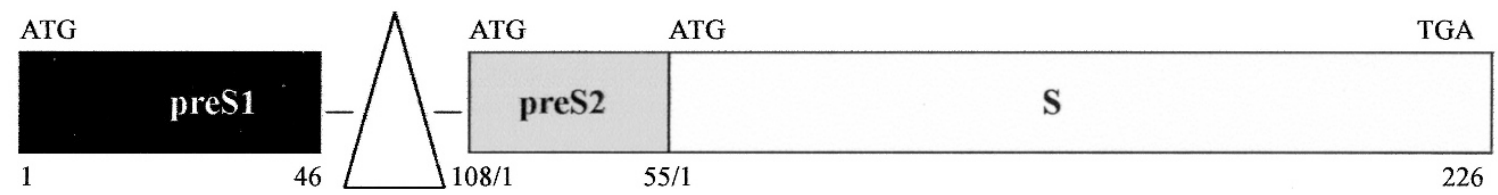

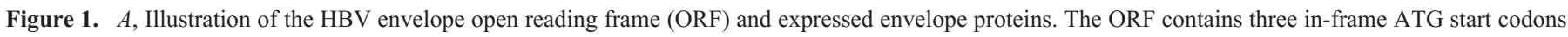

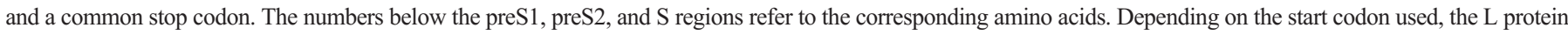

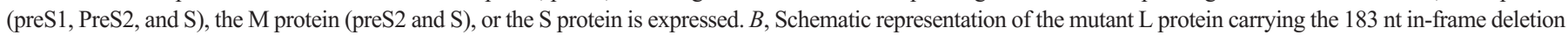
of patient 12. The corresponding deletion of amino acids 47-107 of the L protein is indicated by a triangle.

preS1-deleted viruses encoding mutant L proteins may cause intracellular retention of viral proteins within the ER concomitant with a direct cytopathic effect of the accumulated proteins that ultimately may lead to the development of ground-glass cells and cell death (10-12).

In a recent study, we identified an in-frame 183 nucleotides preS1 deletion in a child (13). Clinical and biochemical follow-up of this patient during the next years showed no subsidence of hepatitis despite seroconversion to anti-HBe. This observation prompted us to analyze the biologic properties of this preS mutant in terms of virus assembly and secretion. Moreover, to evaluate the significance of such mutants in childhood, its prevalence was studied in a large population of chronically infected children.

\section{METHODS}

Patients. The study population was composed of 60 subjects with histologically proven chronic hepatitis B. They were randomly chosen and, except for patient 12 , were independent of subjects described in earlier papers. In a recent report, we identified the deletion mutant of patient 12 (13).

Sera from children were collected from different stages of the disease with a mean age of $9.8 \mathrm{y}$ (range 12 mo to $17.5 \mathrm{y}$ ); 27 were female, 33 were male; 19 had seroconverted to anti-Hbe, and 41 were still HBeAg positive. ALT levels were elevated $(>21 \mathrm{U} / \mathrm{L})$ in 29 patients. All patients were negative for antibodies to hepatitis $\mathrm{C}$ virus, hepatitis $\mathrm{D}$ virus, and HIV. Informed consent was obtained, and the study was approved by the applicable Institutional Review Board.

PCR Amplification and Sequencing. The PCR amplification and sequencing is described in detail in our previous work (13). Briefly, after viral DNA extraction, the preS HBV DNA was amplified using primers P1 and P2 (P1, 5'-GGGTCACCTTATTCTTGT-3', nucleotide 2816-2833; P2, 5'-GTCCTAGGAATCCTGATG-3', nucleotide 173-189). The PCR was performed for 35 cycles at $94^{\circ} \mathrm{C}$ for $1 \mathrm{~min}, 60^{\circ} \mathrm{C}$ for $30 \mathrm{~s}$, and $72^{\circ} \mathrm{C}$ for $1 \mathrm{~min}$ in a thermal cycler (Perkin Elmer Cetus, Norwalk, CT, U.S.A.). The HBV basic core promoter and preCore region of patient 12 was additionally sequenced from samples 10/93 and 06/94. Plus and minus strands were sequenced with primers P1 and P2 using a Dye Terminator Cycle Sequencing Kit (ABI PRISM, Foster City, CA, U.S.A.) in an automated sequencer model 377 (ABI).

Serologic Markers. HBsAg, $\mathrm{HBeAg}$, anti-HBe, anti-HBs, and anti-HBc were assayed using commercial radioimmunoassays (Abbott Laboratories, North Chicago, IL, U.S.A.). HBV DNA was determined semiquantitatively with the "Digene Hybrid Capture II" assay (Abbott Laboratories). The detection limit is $0.5 \mathrm{pg} / \mathrm{mL}$. 

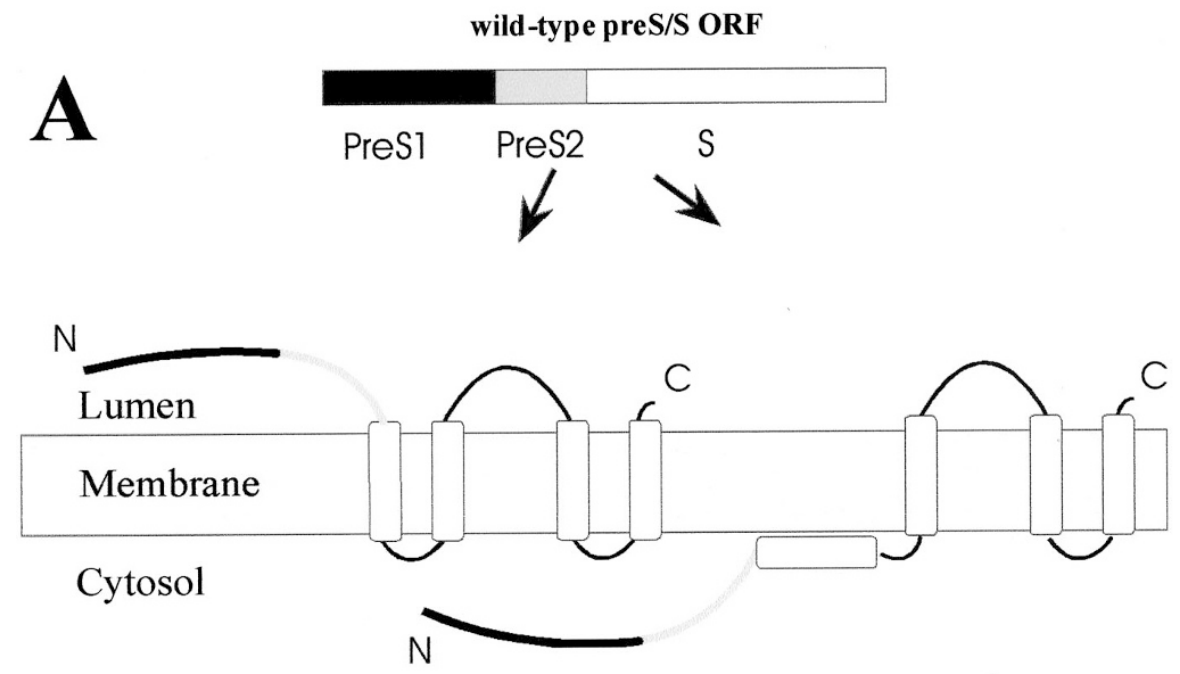

mutant preS/S ORF
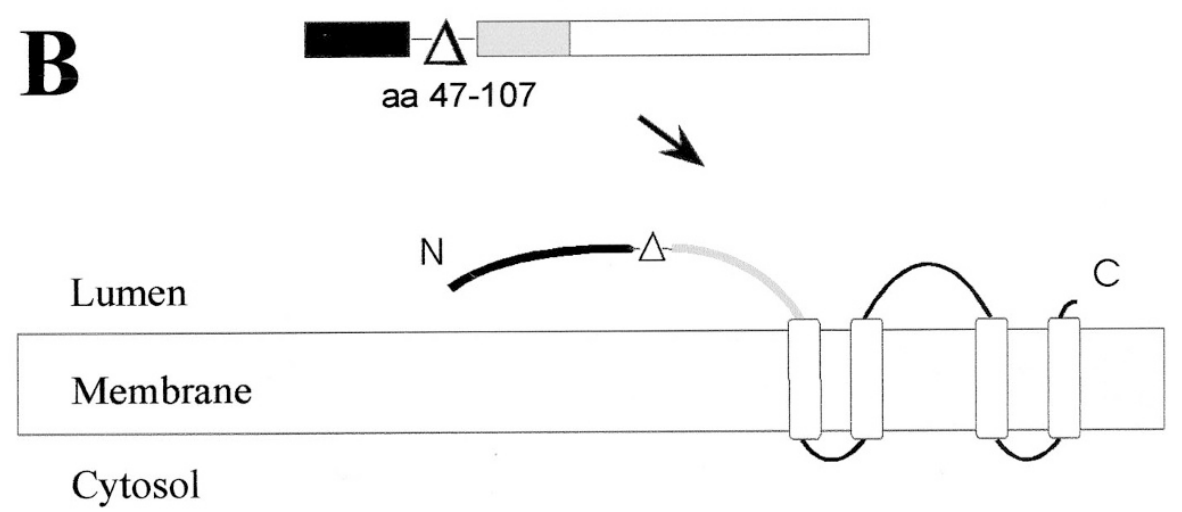

Figure 2. Proposed transmembrane topologies in the ER membrane of wild-type L protein and the deletion mutant lacking amino acids 47-107 within preS1. $A$, Dual topology of the wild-type L protein: approximately one half of preS1 and preS2 of L molecules are located on the cytosolic side of the ER membrane, whereas the other half localizes into the ER lumen. The $\mathrm{C}$-terminal half of $\mathrm{L}$ is known to have four transmembrane segments. $B$, Deletion of amino acids $47-107$ (triangle) of preS1 results in translocation of al preS regions into ER lumen and a uniform topology. N, aminoterminal; $\mathrm{C}$, carboxyterminal.

Plasmid Construction, Expression, and Characterization of Wild-Type and Mutant L Envelope Proteins. For expression of the HBV envelope genes, plasmids pMSV.L and pMSV.S carrying either the L gene or the S gene, respectively, under the transcriptional control of the human metallothionein IIa promoter were used (9). The mutant $\mathrm{L}$ gene, which carries the $183 \mathrm{nt}$ deletion within the C-terminal part of the preS1 domain of the $\mathrm{L}$ protein, was similarly cloned into pMSV (pMSV.L mutant). For in vitro replication of HBV in permissive liver cell lines, plasmid pMHBV, which contains an 1.1-mer of the HBV genome (provided by H. Schaller (14), was used. For preventing expression of the $\mathrm{L}$ envelope protein from this construct, the translational start codon of the $\mathrm{L}$ protein was inactivated by mutagenesis (pMHBV.L $\mathrm{L}^{-}$), as described previously (15). For analyzing expression of wild-type and mutant L genes in transiently transfected COS-7 cells, metabolic pulse-chase labeling of cells with $\left[{ }^{35} \mathrm{~S}\right]$ methionine- cysteine and L-specific immunoprecipitation of the envelope proteins were done as described (9).

For investigating the ability of wild-type and mutant L proteins for packaging of nucleocapsids, virion production was monitored in HuH-7 human hepatoma cells. The cells were maintained in Dulbecco's modified Eagle's medium complemented with $10 \%$ fetal bovine serum at $37^{\circ} \mathrm{C} / 5 \% \mathrm{CO}_{2}$. Cells were grown to $50 \%$ to $60 \%$ confluence before transfection by using the calcium phosphate method. For transfection, $20 \mu \mathrm{g}$ of plasmid pMHBV or its L-negative derivative pMHBV.L $\mathrm{L}^{-}$was used per $10 \mathrm{~cm}$ cell culture dish. For co-transfection, expression plasmids pMSV.L or pMSV.L mutant were added in addition $(3 \mu \mathrm{g})$. The amount of these DNAs was reduced to prevent a block to secretion of the envelope proteins due to overexpressed L protein $(16,17)$. Because the investigated 183 nt deletion removes the HBV S-specific promoter, all transfection experiments were performed with pMSV.S as a co- 
transfecting plasmid to ensure sufficient $\mathrm{S}$ protein synthesis, which is required for virion production (15). Four days after transfection, virions from culture supernatants and nucleocapsids from cellular lysates were isolated by immunoprecipitation using polyclonal rabbit antiserum specific for the HBV envelope or capsid proteins, respectively (15).

Endogenous Polymerase Reaction. Endogenous polymerase reaction (EPR) is a method to detect HBV DNA and similarly to investigate the functionality of the viral polymerase. After immunoprecipitation, the separated virions or nucleocapsids were incubated overnight at $37^{\circ} \mathrm{C}$ with dTTP, dGTP, dCTP, and $\left[\alpha^{32} \mathrm{P}\right] \mathrm{dATP}$. The partially single-stranded HBV DNA is thereby completed by the viral polymerase. After extraction of the viral DNA, the radioactive-labeled DNA can be detected by agarose-gel electrophoresis and PhosphorImager scanning (15).

\section{RESULTS}

PreS Sequences. In one boy (patient 12), a mix of HBV wild-type and preS-deleted particles was found (Fig. 3). By sequencing and alignment to reported HBV sequences, the isolates were shown to belong to genotype $\mathrm{D}$, subtype ayw (18). The in-frame deletion at the C-terminus of the preS1 region included 183-nt and removed amino acids $47-107$ of the large envelope polypeptide (Fig. 1). Fourteen follow-up sera were available and were investigated by PCR. Figures 3 and 4 demonstrate the time of selection of the preS1-deleted HBV particles. No additional preS rearrangements, such as insertions or inversions, were found (data not shown). To show that no other mutation is responsible for the liver cell injury in patient 12 , we sequenced the basic core promoter and preCore region of two different serum samples (samples 10/93 and 06/94). The

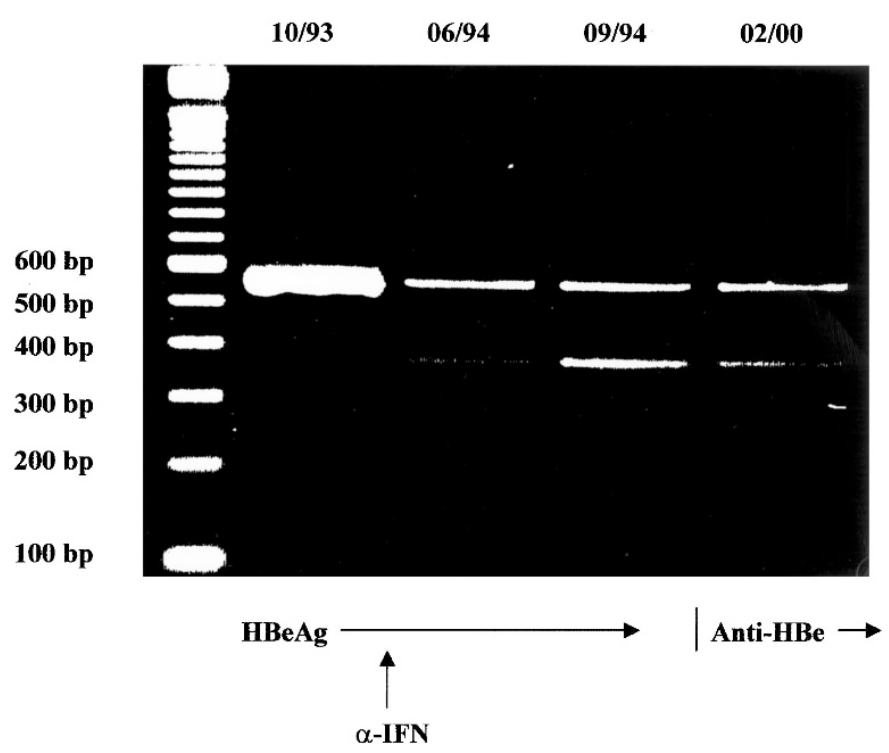

Figure 3. PCR fragments of the preS region from patient 12. Shown are amplification products at four different times of infection. Lane 1, $100 \mathrm{bp}$ length marker; lane 2, PCR product of October 1991; lane 3, June 1992; lane 4, September 1992; lane 5, June 1993. Lane 2 shows a PCR product of the expected size (563 bp). A mix of wild-type and deleted HBV DNA is detected in lanes 3, 4, and 5. The HBV deletion mutant appeared 1 mo after initiation of interferon therapy (arrow).

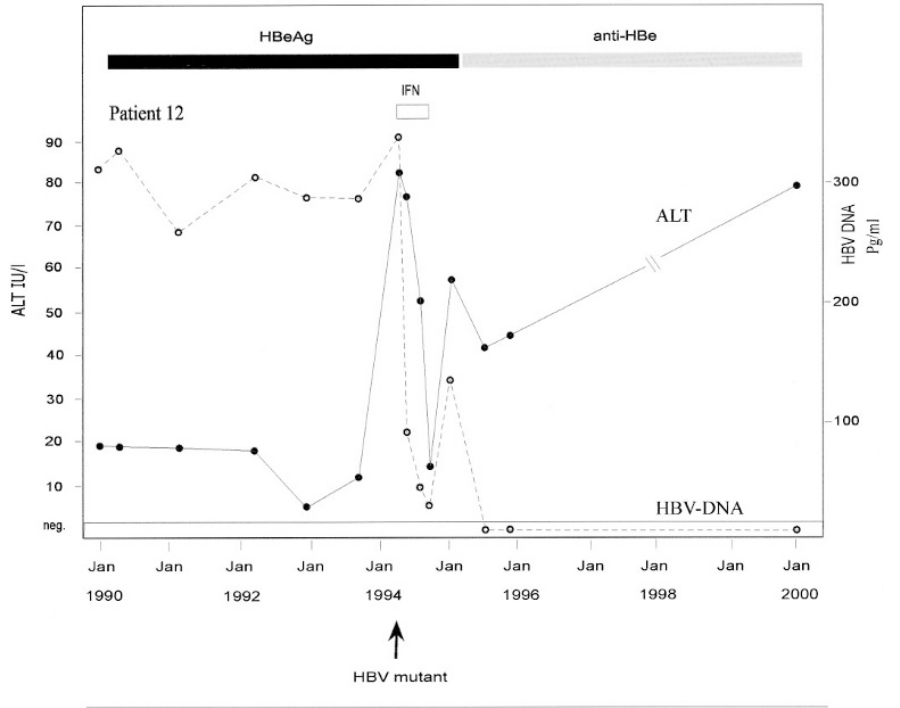

Figure 4. Course of biochemical and serologic markers in patient 12 . Selection of the preS-deletion mutant, demonstrated by the arrow beneath, was associated with a marked increase in ALT level. Despite anti-Hbe seroconversion and disappearance of HBV DNA, the ALT levels remained high. The solid line denotes the biochemical course of ALT, and the dashed line indicates the HBV DNA levels.

14 serial samples were available from the child with the deletion mutant; the highest ALT elevation was $82 \mathrm{U} / \mathrm{L}$. For preventing complications of HBV infection and to lower the infectivity, the boy was treated with interferon- $\alpha 2 \mathrm{~b} 3$ mio. units per $\mathrm{m}^{2}$ of body surface three times a week for 6 mo between March and September 1994. Appearance of the mutant was 1 mo after initiation of interferon therapy.

In each of the 59 children, three to eight follow-up data of ALT levels were available. During follow-up, ALT elevation of more than twice the level than the study serum was seen in 25 children. Of these 25 children, 11 seroconverted to antiHbe, but unlike the patient with the deletion mutant, ALT levels turned to normal values in all of them. No significant mutation known to be associated with liver inflammation in anti-Hbe-positive patients (e.g. mutations at nt position 1762 or 1764 or any $\mathrm{HBeAg}$ minus mutation, or any missense mutation) was identified (data not shown).

Clinical Course of a Patient Before and After Selection of preS-Deleted HBV. The follow-up of patient 12 over $10 \mathrm{y}$ is shown in Figure 4. After vertical infection, the child received a diagnosis of chronic HBV infection. During the first 13 y of life, he remained asymptomatic with serum aminotransferases at normal range. Emergence of the preS deletion was associated with an increase in AST and ALT levels, and hepatitis did not improve even after seroconversion to anti-HBe. Liver biopsy was performed twice. Liver biopsy in 1994 showed in the light microscopy sections of 10 portal tracts. The portal tracts are considerably widened with fibrosis. The structures contained within (bile ductuli, arteries, and veins) are regularly situated. In the stroma of the portal tracts are moderate inflammatory infiltrations, predominantly consisting of lymphocytes as well as some plasma cells and eosinophilic granulocytes. In the periphery of the lobules is some cell necrosis surrounded by lymphocyte infiltration. The central veins are obviously pre- 
served in the needle biopsy. In the lobule is some cell necrosis with slight inflammatory infiltration. Few councilman bodies and glycogen nuclei are present. In the Goldner-stained section is considerable fibrosis of the portal tracts, partially with septal formation. In the Fe-reaction is no siderosis or cholestasis. In the periodic acid-Schiff reaction, the hepatocytes contain a normal amount of stored glycogen. A second biopsy was performed in 1996 but showed no substantial changes.

Mutant L Envelope Protein Is Localized Only to the Lumen of the ER Compartment. The N-glycosylation pattern of the $\mathrm{L}$ protein is a marker for its transmembrane topology (9, 19). Figure 5 shows the glycosylation of wild-type $L$ and mutant L. Non- and single-glycosylation of L (lane 1), typical for wild-type L, is due to the cytosolic retention of the preS1/ preS2 domain of approximately half of the L molecules (see also Fig. 2), where the preS1/S2 domain is available for interaction with the cytosolic nucleocapsid. In contrast, mutant $\mathrm{L}$ appeared in non-, single-, double-, and triple-glycosylation forms (lane 2), indicating that the preS1/2 domain of the protein is completely co-translationally translocated to the lumen of the ER (see also Fig. 2).

Mutant L Envelope Protein Is Unable to Encapsidate Nucleocapsids. The capability of the mutant $\mathrm{L}$ to envelop the nucleocapsid was tested. After expression of viral proteins in HuH-7 cells, virions and nucleocapsids were isolated from cell supernatants and cell lysates, respectively. They were immunoprecipitated with specific antibodies to either virions or nucleocapsids, and viral DNA was marked by EPR. Figure 6

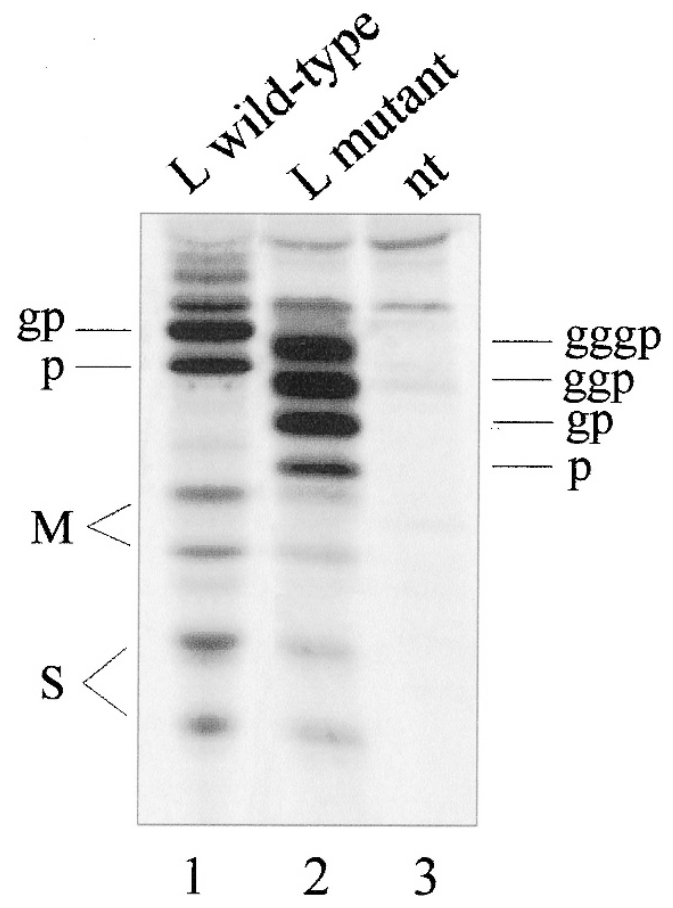

Figure 5. Synthesis and glycosylation of wild-type and mutant L proteins. COS-7 cells transiently expressing the wild-type or the mutant construct were labeled with ${ }^{(35 \mathrm{~S})}$ methionine/cysteine. L proteins from cellular lysates were immunoprecipitated with an L-specific antiserum, fractionated through a polyacrylamide gel, and depicted by PhosphorImager scanning. P, nonglycosylated; gp, ggp, gggp, single-, double, triple-glycosylated forms of L. The HBV $\mathrm{M}$ and $\mathrm{S}$ are also indicated. As a control, nontransfected cells (nt) are shown.

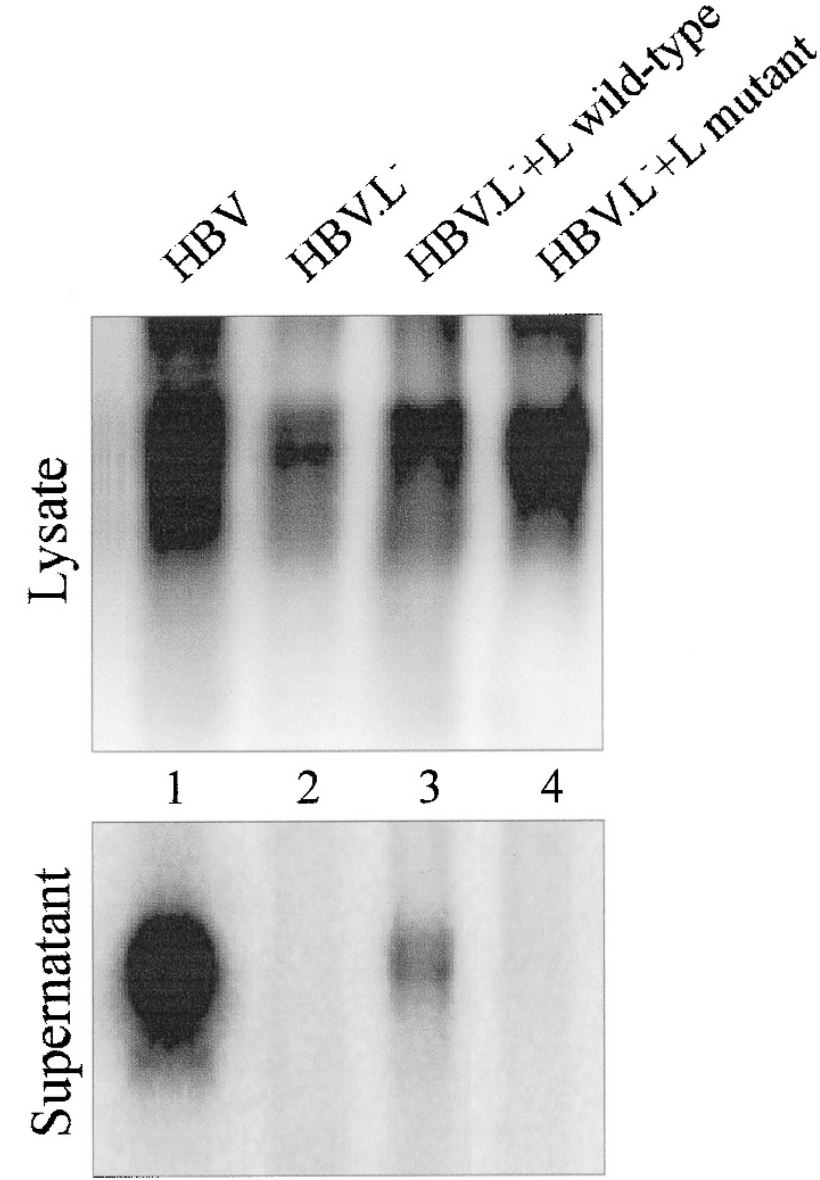

Figure 6. The effect of deleted L protein on viral morphogenesis was analyzed by (co)transfecting plasmids carrying the wild-type or mutant genes into human hepatoma cells. For investigating the mutant $\mathrm{L}$ without $\mathrm{L}$ wild-type expression $\left(\mathrm{L}^{-}\right)$, the first start codon ATG of the preS ORF was mutated in the basic plasmid construct pMHBV. Because the 183-nt deletion removes the HBV S promoter, the S protein was co-transfected. Cellular lysates (top) and supernatants (bottom) were immunoprecipitated with antisera specific to the core and envelope proteins, respectively. By means of the EPR, the viral genomes were labeled and visualized by agarose electrophoresis and PhosphorImaging scanning.

demonstrates that expression of the HBV wild-type L-protein in cis supports viral morphogenesis (lane 1), as is the case for $\mathrm{L}$ expression in trans (lane 3). In contrast, no viral encapsidation and thus virion release is observed in the supernatant of cells after transfection with HBV plasmids containing the mutant L (lane 4) or no L protein (lane 2). The upper panel shows that in all cell lysates, irrespective of the transfected plasmids, sufficient nucleocapsids were available for packaging. Therefore, not the nucleocapsid formation but rather its encapsidation was blocked by the L protein.

Mutant L Envelope Protein Is Transdominant Negative. For testing whether the defect in viral encapsidation of mutant $\mathrm{L}$ can be restored by coexpression of wild-type L, plasmid pMSV.L was expressed together with plasmid pMSV.L mutant in trans in HuH-7 cells transfected with the L-deficient HBV genome. Transfection, immunoprecipitation, and EPR were performed as described above. The upper panel of Figure 7 shows that in all cell lysates, HBV DNA was detected in similar concentrations. The lower panel depicts the effects on 

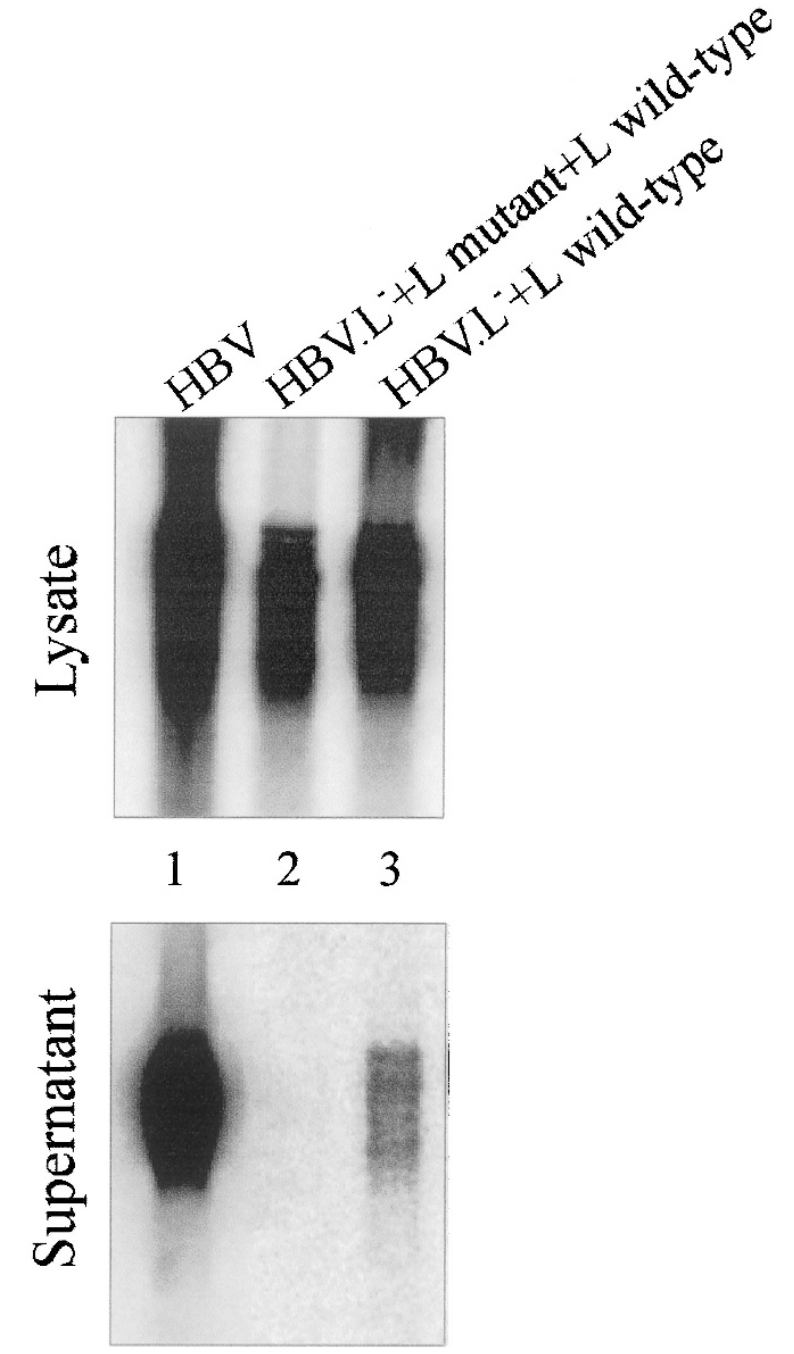

Figure 7. For investigating whether the defect in packaging of nucleocapsids by mutant $\mathrm{L}$ protein can be rescued by coexpression of wild-type $\mathrm{L}$, both genes were co-transfected along with pMHBV.L. As above, the S protein was also provided. Top, Detection of nucleocapsids in cellular lysates after immunoprecipitation and EPR. Bottom, Virion secretion in the culture medium. In lane 2 , no virion release is detected, indicating that the mutant $\mathrm{L}$ protein suppresses viral packaging even in the presence of wild-type $\mathrm{L}$.

HBV morphogenesis. Lane 3 demonstrates that coexpression of wild-type $\mathrm{L}$ and mutant $\mathrm{L}$ is not sufficient to restore the encapsidation deficiency, which indicates that the L-deleted protein acts in a transdominant negative manner in viral morphogenesis.

\section{DISCUSSION}

Rearrangements in the HBV preS region are frequently present in adults and were often associated with progressive liver disease $(4,20,21)$. In this study, we investigated the impact of a HBV preS deletion mutant on the clinical course of infection in one child. As an addendum, we screened a large population of other patients for deletions in this part of the genome. According to our data, unlike in adults, preS deletions are rare in children and were documented only in one child. During the 10-y follow-up of this boy, the emergence of the mutation was accompanied by a marked increase of liver enzymes, which persisted despite seroconversion to anti-HBe and not detectable HBV DNA by common liquid hybridization assays. The functional characterization of the mutant gene revealed a defect in viral packaging and subsequently virion secretion. This defect can be explained by the dual transmembrane topology of the large envelope protein in the ER membrane. We recently determined the sequence that is responsible for the cytosolic orientation (22). Because this region is completely deleted in the HBV genome derived from our patient, the mutant $\mathrm{L}$ protein is not accessible for interaction with the cytosolic viral nucleocapsid, which results in nonpackaging of nucleocapsids and thus in a defect of virion assembly, as assayed in an in vitro replication assay for HBV. It was surprising that this defect could not be restored by coexpression of the wild-type L protein. This is in contrast to results from Melegari et al. (11), who published data in which the expression of $\mathrm{S}$ in trans was sufficient to rescue viral morphogenesis. In fact, all deleted HBV particles were extracted from peripheral blood samples, indicating that they are localized extracellularly. One potential explanation for this discrepancy is that the ratio of expressed wild-type $\mathrm{L}$ to mutant $\mathrm{L}$ is critical, which is supported by the finding that the described preS deletion has always been found in coexistence with the HBV wild type. If this is true, then it can be suspected that at least a portion of viral proteins accumulate within the ER, because the ratios of wild-type and mutant strains may differ in the organism. Studies in cell culture and in transgenic mice can explain our in vivo observation of liver inflammation induced by the emergence of HBV-deleted genomes. In these investigations, it was demonstrated that the retention of viral proteins has a direct cytopathic activity $(10,23)$.

The reason for the selection of this mutant can only be speculated. It is striking that in all cases reported, the $183 \mathrm{nt}$ preS1 deletion was selected after treatment with interferon, which has the goal to enhance the host's immunologic pressure on viral elimination. Therefore, it is conceivable that the virus may have some advantage against immune surveillance by deleting B- and T-cell epitopes, which are known to cluster in the preS1 region (24).

Regarding hepatitis B variants in childhood, an additional finding of this study should be stressed. Compared with studies in adulthood, the frequency of mutations in young chronic carriers with stable liver disease was low, as supported by our previous investigations $(13,25,26)$. One reason may be the lack of neutral sequence drift during chronic carriage. Therefore, it is easier to put the identified rearrangements in the context of the course of infection, which can be hampered when mutations occur frequently and distribute over the entire genome.

In this study, the impact of HBV-deleted genomes was investigated in chronically infected children. In contrast to adults, the prevalence of these rearrangements was low. However, our clinical and functional studies strongly suggest that such a mutant caused ongoing liver inflammation despite the appearance of $\mathrm{HBe}$ antibodies followed by a marked decrease of viral DNA. 
Acknowledgments. We thank C. Foerster for excellent technical assistance. The support provided by Prof. P.G. Höher Institute of Microbiology, Immunology and Virology Klinikum Wuppertal, Germany, is highly appreciated.

\section{REFERENCES}

1. Liang TJ, Hasegawa K, Rimon N, Wands J, Ben-Porath E 1991 A hepatitis B virus mutant associated with an epidemic of fulminant hepatitis. N Engl J Med 324:17051709

2. Baumert TF, Rogers SA, Hasegawa K, Liang TJ 1996 Two core promoter mutations identified in a hepatitis B virus strain associated with fulminant hepatitis result in enhanced viral replication. J Clin Invest 98:2268-2276

3. Günther S, Piwon N, Iwanska A, Schilling R, Meisel H, Will H 1996 Type, prevalence and significance of core promoter/enhancer II mutations in hepatitis B viruses from immunosuppressed patients with severe liver disease. J Virol 70:8318 8331

4. Bock C-T, Tillmann HL, MaschekH-J, Manns MP, Trautwein C 1997 A preS mutation isolated from a patient with chronic hepatitis B infection leads to virus retention and misassembly. Gastroenterology 113:1976-1982

5. Bartholomew MM, Jansen RW, Jeffers LJ, Reddy KR, Johnson LC Bunzendahl H, Condreay LD, Tzakis AG, Schiff ER, Brown NA 1997 Hepatitis-B-virus resistance to lamivudine given for recurrent infection after orthotopic liver transplantation. Lancet 349:20-22

6. Zuckerman AJ, Thomas HC 1999 Viral Hepatitis. Churchill Livingston, Hong Kong, pp 141-173

7. Günther S, Fischer L, Pult I, Sterneck M, Will H 1999 Naturally occurring variants of hepatitis B virus. Adv Virus Res 52:25-137

8. Wirth S, Gerner P, Friedt M, Lausch E, Truebel H, Winter K 1998 Hepatitis B virus mutants in HBsAg positive children. Acta Gastroenterol Belg 61:185-188

9. Prange R, Streeck RE 1995 Novel transmembrane topology of the hepatitis B virus envelope proteins. EMBO J 14:247-256

10. Xu Z, Yen TS 1996 Intracellular retention of surface protein by a hepatitis B virus mutant that releases virion particles. J Virol 70:133-140

11. Melegari M, Scaglioni P, Wands JR 1997 The small envelope protein is required for secretion of a naturally occurring hepatitis B virus mutant with pre-S1 deleted. J Virol 71:5449-5454

12. Chisari FV, Klopchin K, Moriyama T, Pasquinelli C, Dunsford HA, Sell S, Pinker CA, Brinster RL, Palmiter RD 1989 Molecular pathogenesis of hepatocellular carcinoma in hepatitis B virus transgenic mice. Cell 59:1145-1156
13. Gerner PR, Friedt M, Oettinger R, Lausch E, Wirth S 1998 The hepatitis B virus seroconversion to anti-HBe is frequently associated with HBV genotype changes and selection of preS2 defective particles in chronically infected children. Virology 245:163-172

14. Radziwill G, Tucker W, Schaller H 1990 Mutational analysis of the hepatitis B virus $\mathrm{P}$ gene product domain structure and RNase H activity. J Virol 64:613-620

15. Löffler-Mary H, Dumortier J, Klentsch-Zimmer C, Prange R 2000 Hepatitis B virus assembly is sensitive to changes in the cytosolic $\mathrm{S}$ loop of the envelope proteins. Virology 270: 358-367

16. Cheng C, Smith K, Moss B 1986 Hepatitis large surface protein is not secreted but is immunogenic when selectively expressed by recombinant vaccinia virus. J Virol 60:337-344

17. Chisari FV, Filippi P, McLachlan A, Milich D, Riggs M, Lee S, Palmiter R, Pinkert C, Brinster R 1986 Expression of hepatitis B large envelope polypeptide inhibits hepatitis B surface antigen secretion in transgenic mice. J Virol 60:880-887

18. Norder H, Hammas B, Löfdahl S, Courouce AM, Magnius LO 1992 Comparison of the amino acid sequences of nine different serotypes of hepatitis B surface antigen and genomic classification of the corresponding hepatitis B virus strains. J Gen Virol 73:1201-1208

19. Hubbard SC, Ivatt RJ 1981 Synthesis and processing of asparagine-linked oligosaccharides. Annu Rev Biochem 50:555-583

20. Nakajima E, Minami M, Ochiya T, Kagawa K, Okanoue T 1994 PreS1 deleted variants of hepatitis B virus in patients with chronic hepatitis. J Hepatol 20:329-335

21. Santantonio T, Jung MC, Schneider R, Fernholz D, Milella M, Monno L, Pastore G, Pape GR, Will H 1992 Hepatitis B virus genomes that cannot synthesize pre-S2 proteins occur frequently and as dominant virus populations in chronic carriers in Italy. Virol 188:948-952

22. Löffler-Mary H, Werr M, Prange R 1997 Sequence-specific repression of cotranslational translocation of the hepatitis B virus envelope proteins coincides with binding of heat shock protein Hsc70. Virology 235:144-152

23. Chisari FV, Klopchin K, Moriyama T, Pasquinelli C, Dunsford HA, Sell S, Pinkert CA, Brinster RL, Palmiter RD 1989 Molecular pathogenesis of hepatocellular carcinoma in hepatitis B virus transgenic mice. Cell 59:1145-1156

24. Milich DR 1988 T- and B-cell recognition of hepatitis B viral antigens. Immunol Today 9:380-386

25. Bahn A, Gerner P, Martine U, Bortolotti F, Wirth S 1997 Detection of different viral strains of hepatitis B virus in chronically infected children after seroconversion from HBsAg to anti-HBs indicating viral persistence. J Hepatol 27:973-978

26. Friedt M, Gerner P, Lausch E, Trübel H, Zabel B, Wirth S 1999 Mutations in the core promoter and the precore region of hepatitis B virus and their selection in children with fulminant and chronic hepatitis B. Hepatology 29:1252-1258 